\title{
A expressão do passado absoluto em variedades argentinas
}

\author{
The expression of the absolute past in argentine varieties
}

\author{
Leandro Silveira de Araújo* \\ Universidade Federal de Uberlândia \\ Uberlândia, Minas Gerais, Brasil
}

Resumo: Este trabalho analisa a expressão do passado absoluto (PA - El Ministerio de Seguridad difundió ayer la identidad de las víctimas) em Buenos Aires e San Miguel de Tucumán. O interesse decorre da variação observada entre as formas do perfecto compuesto (PC - han tirado) e simple (PS - difundio) na expressão desse sentido e das descrições ainda limitadas, que proporcionam um conhecimento incipiente sobre o uso do PC e do PS expressando PA nas duas regiões argentinas. Em complemento, o estudo diacrônico dessas formas indica a existência de um processo de mudança que opera sobre o PC - originalmente marcada por valores aspectuais -, transformando-a em uma construção temporal que expressa valor de anterioridade à fala, isto é, antepresente e, mais adiante, passado absoluto. A fim de proceder ao estudo desse comportamento do pretérito perfecto, valemo-nos do referencial teórico-metodológico da Sociolinguística Variacionista, isso para identificar o encaixamento dessa variação nas variedades e avaliar se os estados descritos correspondem a diferentes estágios de evolução. A análise de dados pautou-se em um corpus constituído por enunciados de entrevistas radiofônicas, pois esse gênero propicia um contexto para a recorrência do PA e resgata uma fala mais espontânea. Finalmente, procedemos a análise multivariada que indicou estatisticamente fatores que ajudam a explicar o encaixamento dessa variação nas duas variedades diatópicas. Os resultados apontam um uso mais recorrente da forma composta em San Miguel de Tucumán. Em especial, essa variedade aponta um percentual maior no uso do PC no PA. Em Buenos Aires, por sua vez, observa-se um uso quase categórico do PS no PA.

Palavras-chave: Pretérito Perfecto. Temporalidade. Variação Linguística. Argentina. Espanhol.

Abstract: This paper analyzes the expression of the absolute past (PA - El Ministerio de Seguridad difundio ayer la identidad de las victimas) in Buenos Aires and San Miguel de Tucumán. The interest comes from the variation between the forms of the perfecto compuesto (PC - han drawn) and simple (PS - diffused) in the expression of this tense and the still limited descriptions, which provide an incipient knowledge about the use of PC and PS expressing PA in both Argentine regions. In addition, the diachronic study of these forms indicates the existence of a process of change that operates on the PC - originally marked by aspectual values -, transforming it into a temporal construction that expresses the value of anteriority to speech and, later, absolute past. In order to study the behavior of the preterito perfecto, we use the theoretical-methodological framework of Variationist Sociolinguistics to identify the fit of this variation in the varieties and to evaluate if the states described correspond to different stages of evolution. The data analysis was based on a corpus composed of radiophonic interview, because this textual genre provides a context for the use of the PA and rescues a more spontaneous speech. Finally, we performed the multivariate analysis that indicated statistically factors that help explain the fit of this variation in the two diatopic varieties. The final results indicate a more recurrent use of the composite form in San Miguel de Tucumán. In particular, this variety points to a higher percentage of PC use in the PA. In Buenos Aires, in turn, there is an almost categorical use of PS in the PA.

Keywords: Perfect; Tense; Temporality. Linguistic Variation. Argentina. Spanish.

* Docente da Universidade Federal de Uberlândia. E-mail: araujoleandrosilveira@gmail.com 


\section{INTRODUÇÃO}

Visamos com este trabalho observar a expressão do passado absoluto (PA - El Ministerio de Seguridad difundió ayer la identidad de las víctimas) em duas variedades argentinas. Como veremos, o interesse decorre da variação observada entre as formas do pretérito perfecto compuesto (PPC - han tirado) e simple (PPS - difundió) na expressão dessa concepção temporal e das descrições ainda limitadas, que proporcionam um conhecimento incipiente sobre o uso do PPC e do PPS expressando passado absoluto nas regiões noroeste e bonaerense da Argentina. Em complemento, o estudo diacrônico dessas formas indica a existência de um processo de mudança que opera sobre a forma composta - originalmente marcada por valores aspectuais (resultado/continuidade) -, transformando-a em uma construção temporal que expressa valor de anterioridade à fala, isto é, antepresente e, mais adiante, passado absoluto. Consequentemente, a mudança no PPC ocasionou um rearranjo no uso do PPS. A fim de proceder ao estudo desse comportamento heterogêneo do pretérito perfecto, recorremos ao referencial teóricometodológico da Sociolinguística Variacionista, isso para identificar o estado de uso das formas temporais nas duas variedades diatópicas. A análise de dados pautou-se em um corpus constituído por enunciados pertencentes a entrevistas radiofônicas das variedades, pois esse gênero discursivo propicia um contexto adequado para a recorrência desses valores, além de resgatar uma fala mais espontânea. Finalmente, procedemos a uma análise multivariada que, indicou, por meio de dados estatísticos, fatores que ajudam a explicar o encaixamento dessa variação nas variedades diatópicas da língua.

Em síntese, a problemática orientadora deste estudo procede não apenas do desencontro entre a norma-padrão e o uso efetivamente observado das formas do pretérito perfecto em espanhol, mas também do reconhecimento de um complexo e extenso processo de mudança das formas do pretérito perfecto nas línguas românicas, de modo geral, e nas variedades do espanhol, mais especificamente. Soma-se a esse cenário a observação sincrônica da variação existente entre o PPS e o PPC sob as diferentes dimensões extralinguísticas de análise, com especial destaque à dimensão diatópica - muitas vezes abordada de modo impressionista e generalizador.

Frente a essa problemática, surge o interesse em descrever como as formas do pretérito perfecto atuam na expressão do passado absoluto nas variedades de Buenos Aires e San Miguel de Tucumán, isso para avaliarmos a dimensão da variação existente entre o PPC e o PPS nessas variedades diatópicas. Repousa sobre esse objetivo a hipótese de que "conforme a variedade diatópica, o PPS e o PPC operam conjuntamente, isto é, estão em variação na expressão do referido contexto temporal”.

\section{PRESSUPOSTOS INVESTIGATIVOS}

A fim de facilitar a compreensão dos objetivos deste estudo, apresentaremos nesta seção a concepção de passado absoluto na língua espanhola e como as formas do pretérito perfecto operam na expressão desse valor temporal. Com esse propósito, iniciamos com a observação de como a norma padrão da língua descreve o funcionamento das formas 
verbais do pretérito perfecto. Em seguida, contrapomos essas informações com os dados já existentes sobre o uso dos pretéritos nas variedades diatópicas argentinas. Esse caminho investigativo permitirá o leitor compreender os dados que apresentaremos sobre a expressão do passado absolutos em Buenos Aires e San Miguel de Tucumán.

\subsection{A CONCEPÇÃO DE PASSADO ABSOLUTO}

Rojo e Veiga (1999) mostram-nos que o tempo da língua fundamenta-se no estabelecimento de um ponto zero, que, por sua vez, coincide com o momento de enunciação. De maneira que "cada ato linguístico converte-se em seu próprio centro de referência temporal, com respeito ao qual os acontecimentos podem ser anteriores, simultâneos ou posteriores" (ROJO, VEIGA, 1999, p.2873). Assim, as relações temporais no tempus ${ }^{1}$ dão-se a partir de uma referência implícita (ponto zero) que é criada e ancorada arbitrariamente no momento de fala, por isso a localização temporal de um evento dependerá de sua relação com o momento de enunciação - daí decorre o caráter dêitico que se atribui ao tempus, uma categoria linguística que se constrói e se organiza a partir da enunciação.

No entanto, é importante salientar que nem sempre a relação com o momento de enunciação é estabelecida de modo explícito e direto, posto que um valor temporal pode construir-se também a partir de outra referência temporal, a qual, por sua vez, manterá uma relação mais estreita com o momento de fala. Assim, pode-se afirmar que "a temporalidade linguística é uma categoria dêitica múltipla e flexível que gira em torno de mais de um eixo, e que é substancialmente relativa" (HERNÁNDEZ ALONSO, 1996, p.412).

Há de se considerar ainda a existência de ao menos três instâncias temporais envolvidas na expressão linguística do tempo, a saber: o momento da fala (MF), isto é, da enunciação, que está em contínua construção e coincide com o momento presente do enunciador; o momento das situações descritas $(\mathrm{ME})$ e o momento de referência $(\mathrm{MR})$, isto é, o momento em "que idealmente se situa o falante, deslocando-se em pensamento para o passado ou para o futuro" (CASTILHO, 1966, p.106). Será, portanto, a combinação desses três momentos que permitirá a expressão linguística do tempo, evidenciando que toda medição temporal no verbo é relativa e sustentada por um tripé.

De acordo com o que nos revelou o estudo de Andrés Bello² (1972 [1841], 2004 [1847]), o valor de passado absoluto (PA) significa a anterioridade do atributo à origem, que é o próprio momento de enunciação (BENVENISTE, 2006). No entanto, conforme

\footnotetext{
${ }^{1}$ Nota-se em algumas línguas a diferenciação lexical entre o conceito de tempo não linguístico (tempo cronológico, físico e psicológico) e a expressão do tempo linguístico por meios gramaticais. Esse é o caso do inglês, em que time e tense expressam os respectivos valores. A fim de reproduzir essa distinção e evitar a ambiguidade decorrente da polissemia existente na palavra "tempo", usaremos, neste trabalho, tempo e a forma latina tempus (com o plural tempora).

2 Andrés Bello é gramático cofundador da tradição moderna descritiva da língua castelhana e propõe a categorização do passado na língua espanhola em cinco âmbitos temporais: (i) o pretérito, (ii) o copretérito, (iii) o antepresente, (iv) o antepretérito e o (v) antecopretérito, para os quais correspondem, respectivamente, as cinco formas de passado que se encontram disponíveis no sistema da língua: amé, amaba, he amado, hube amado e habia amado.
} 
apresentado suscintamente na subseção anterior, há outros valores temporais que, direta ou indiretamente, também expressam anterioridade ao MF. A fim de melhor definir os traços do PA, a figura 1 faz um esboço da expressão do passado em espanhol, segundo Rojo (1974):

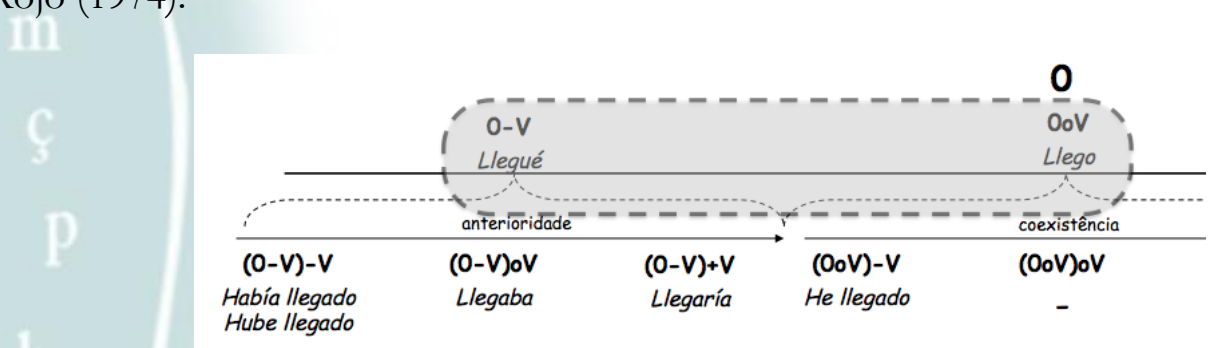

Figura 1: Da expressão do passado absoluto em espanhol segundo Guillermo Rojo³.

Observemos que, na notação do autor, representa-se o passado absoluto por meio de " $0-\mathrm{V}$ " (lleguê), dado que nos indica que a relação de anterioridade ao momento de enunciação (0) é construída a partir de uma relação direta com " 0 " - dai decorre o caráter absoluto atribuído ao valor. Em complemento, Cartagena (1999) associa o sentido de PA ao pretérito perfecto simple (PS) e afirma que essa forma, do mesmo modo que as demais formas de valor absoluto, delineia um segmento temporal primário a partir do ponto zero. Assim,

[...] o presente marca a coexistência [âmbito primário de coexistência], o paralelismo do falar com um ponto do tempo real, em relação ao qual as formas do pretérito perfecto simple e do futuro indicam anterioridade [âmbito primário de retrospectividade] y posterioridade [âmbito primário de prospectividade], respectivamente (CARTAGENA, 1999, p.2937)4.

Notemos que a atribuição do sentido de PA refere-se à envoltura temporal que abarca aquilo que pertence ao "âmbito primário de retrospectividade" e, portanto, já não faz parte do presente. Os enunciados que seguem ilustram essa concepção temporal:

(1) $[\ldots]$ ayer hablé con los periodistas $[\ldots]^{5}$

(2) El año pasado estuve haciendo la consigna de Arnold Wesker" $<$ B3 $>$.

3 Guillermo Rojo $(1974,1990,1999)$ destaca que cada um dos tempora compõe-se necessariamente de um vetor primário, definido por uma das três coordenadas estabelecidas diretamente em relação ao ponto central (0): de anterioridade $(-\mathrm{V})$, de simultaneidade $(\mathrm{oV})$ e de posterioridade $(+\mathrm{V})$ e cujo papel fundamental é a (1) expressão da relação temporal primária dos tempos absolutos ou a (2) especificação de um ponto de referência dos tempos relativos. Nesse postulado, portanto, a relação temporal primária ocupará sempre o vetor $(V)$ ao extremo direito da notação, ao posso que todo o restante, à esquerda, irá se destinar à expressão do ponto de referência, que, nas palavras de Rojo e Veiga (1999, p.2882), "pode ser a origem ou mesmo um ponto situado em relação a ela, é o que estabelece a situação no eixo temporal do momento em relação ao qual as formas expressam a relação primária.” Para maiores esclarecimentos sobre a proposta do autor, sugerimos a leitura das análises de Freitag (2005) e Araujo (2013, 2017).

4 Original: "[...] el presente marca la coexistencia [ámbito primario de coexistencia], el paralelismo del hablar con un punto del tiempo real, respecto del cual las formas de pretérito perfecto simple y de futuro indican anterioridad [ámbito primario de retrospectividad] y posterioridad [ámbito primario de prospectividad], respectivamente" (CARTAGENA, 1999, p.2937).

5 Enunciado retirado de uma entrevista radiofônica difundida pela rádio Cadena 3, de Córdoba/Argentina $(13 / 06 / 2010)$. 
É pertinente notar o papel dos marcadores temporais em ressaltar o sentido suscitado pela forma verbal. Isso porque, ao dizer "ayer" ou "el año pasado", indica-se a abrangência do "âmbito primário de restrospectividade" referido. Em outras palavras, ao usar esses marcadores destaca-se que a situação descrita já não faz parte do "âmbito de coexistência" - no qual vigoraria "hoje" e "neste ano", respectivamente - mas do âmbito temporal já concluído do ayer/ año pasado. É nesse sentido que Alarcos Llorach (1980, p.25) descreve haver uma tendência do tempus de passado absoluto em se associar "com os advérbios que indicam que a ação produz-se num período de tempo no qual não está incluído o momento presente da fala".

Em continuidade, a aplicação à língua espanhola do postulado teórico de Reichenbach (2004 [1947]) também nos revela a forma do pretérito perfecto simple (trabajê) associando-se à expressão do passado absoluto (ME,MR-MF). Conforme mostra a figura 2, o referido âmbito temporal corresponde a situações (ME) que estão contidas no momento de referência passado (R-Passado) e que estabelecem uma relação de simultaneidade com ele.

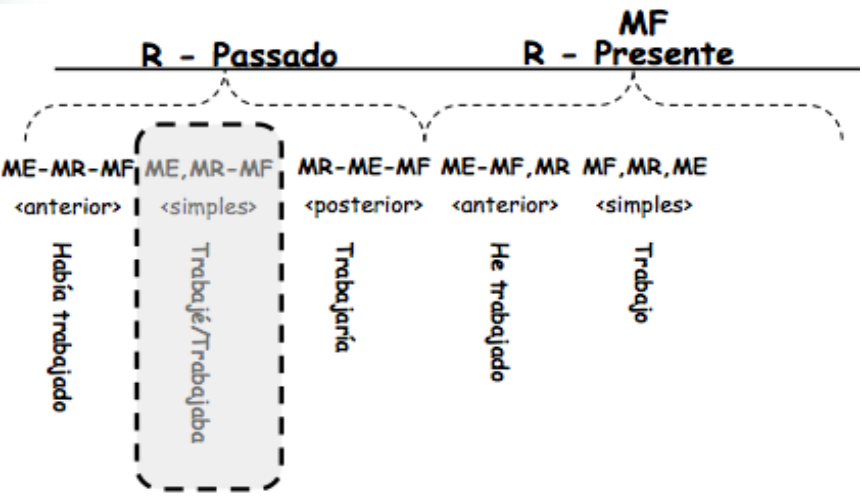

Figura 2: Da categorização do passado absoluto na língua segundo Reichenbach

Por fim, para Comrie (2000 [1985]), o sentido fundamental do PA é apenas localizar uma situação como anterior ao presente, sem se preocupar, portanto, em informar que se trata de uma situação concluída, isto é, que não se estende até ou além do presente. Segundo o autor, é por meio de uma implicatura conversacional que o falante se inteira da conclusão do fato descrito, posto que

Esse último ponto decorre da máxima da relação (relevância) de Grice, na medida em que, em igualdade de circunstâncias, as declarações sobre o momento presente são mais relevantes do que aqueles sobre outros tempos, de modo que o uso de uma forma explicitamente localizando uma situação no passado sugere que essa situação não se mantém no presente, caso contrário, o tempo presente seria usado (COMRIE; 2000, p.41) .

A síntese do valor do passado absoluto, portanto, pode ser mais bem entendida por meio da Figura 3, na qual encontramos uma situação (ME) anterior ao momento de

${ }^{6}$ Original: "This last point follows from Grice's maxim of relation (relevance), in that, other things being equal, statements about the present moment are more relevant than those about other times, so that use of a form explicitly locating a situation in the past suggests that that situation does not hold at the present, otherwise the present tense would be used' (COMRIE, 2000 [1985], p.41) 
enunciação, cuja perspectiva (MR) coincide com o ME ou é imediatamente posterior a ele - mas sempre anterior ao momento de fala (MF)" (HERNÁNDEZ ALONSO, 1996, p.428).

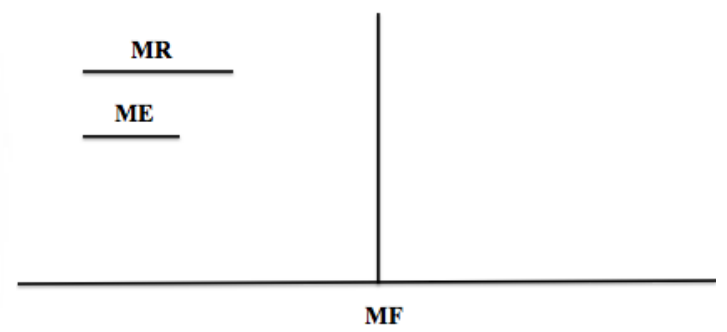

Figura 3: Da síntese do valor de passado absoluto Fonte: Hernández Alonso (1996, p.428) ${ }^{7}$.

\subsection{EXPRESSÃO DO PASSADO ABSOLUTO EM ESPANHOL: NORMA PADRÃO}

A expressão do PA na língua espanhola tem sido tradicionalmente associada à forma do pretérito perfecto simple. Essa recorrente associação se deve, em parte, a que a partir sua origem, no latim, a forma do PS estava vinculada à expressão de situações passadas concluídas, isto é, marcadas pelo traço aspectual de perfectum (terminativo) e pelo valor temporal de PA. Ademais, nota-se que desde sua forma embrionária o perfecto simple "tende a se definir como uma forma bastante estável que geralmente expressa ação terminada no passado" (RODRÍGUEZ LOURO, 2008, p.2).

Conforme nos aponta a "Nueva gramática de la lengua española" (RAE, 2009), a denominação pretérito perfecto simple é composta de três características importantes para a compreensão de seu funcionamento. A primeira corresponde a um traço temporal, isto é, dêitico ou referencial (pretérito); a segunda faz referência a uma informação de ordem aspectual (perfecto) e, por fim, há ainda a informação correspondente a sua morfologia (simple). Assim, a Real Academia Española atribui fundamentalmente o valor de passado absoluto ao pretérito perfecto simple, posto que essa forma faz referência a situações pretéritas terminadas, com os limites de início e fim marcados.

\begin{tabular}{|c|c|c|c|c|c|c|c|c|c|c|c|c|c|c|c|}
\hline \multirow{2}{*}{\multicolumn{2}{|c|}{ Valores }} & \multicolumn{14}{|c|}{ Autores } \\
\hline & & 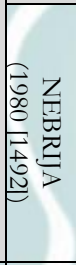 & 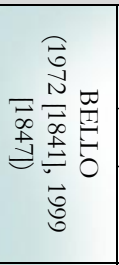 & 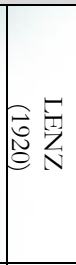 & 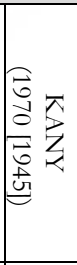 & 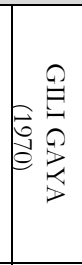 & 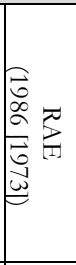 & 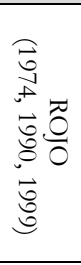 & 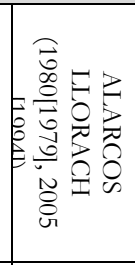 & 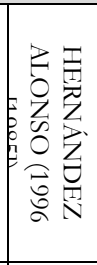 & 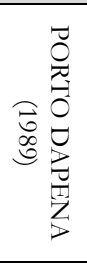 & 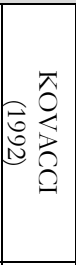 & 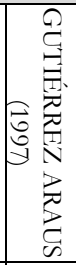 & 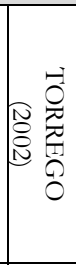 & 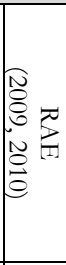 \\
\hline 1 & $\begin{array}{l}\text { Passado } \\
\text { Absoluto }\end{array}$ & + & + & + & + & + & + & + & + & + & + & + & + & + & + \\
\hline 2 & Antecipativo & - & - & + & + & + & - & - & - & - & - & - & - & - & + \\
\hline 3 & Antepretérito & - & - & - & - & - & - & - & - & - & + & - & - & - & - \\
\hline 4 & Experiencial & - & - & - & - & - & - & - & - & - & - & - & - & - & + \\
\hline
\end{tabular}

Quadro 1: Dos valores atribuídos ao PS pela norma gramatical.

${ }^{7}$ As demais figuras, tabelas e quadros deste artigo são de nossa autoria, apenas a figura 3 é retirada da fonte citada. 
Conforme sintetiza o quadro 1, parece haver um acordo sobre a atribuição do valor de PA ao PS, tanto que, já na primeira gramática da língua espanhola, lê-se que o "passado acabado é aquele em que alguma coisa se fez, como eu amei" (NEBRIJA, 1980 [1492], p.187).

Por seu turno, Kany (1970) observa "o espanhol moderno baseado na melhor prática e nas melhores normas" e também atribui ao PS a expressão de "uma ação completa no passado". De igual maneira, os demais autores apresentados no quadro 1 mostram que "o perfecto simple designa um fato sucedido no passado e que teve um limite nesse mesmo passado" (ALARCOS LLORACH, 1980, p.33). Contudo, o quadro 1 também indica ser possível encontrarmos alguns pouco gramáticos que identificam outros sentidos no uso do PS, como o antecipativo etc.

\begin{tabular}{|c|c|c|c|c|c|c|c|c|c|c|c|c|c|c|c|c|c|c|c|}
\hline \multirow{2}{*}{\multicolumn{2}{|c|}{ VALORES }} & \multicolumn{18}{|c|}{ AUTORES } \\
\hline & & 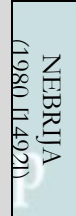 & 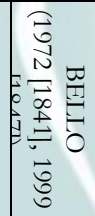 & 零 & 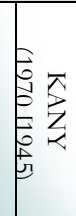 & 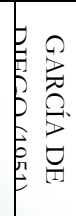 & 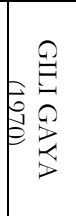 & 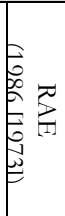 & 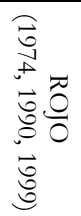 & 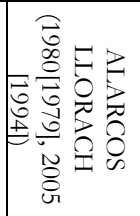 & 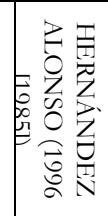 & 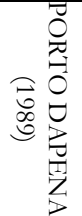 & $\begin{array}{ll} & \pi \\
0 & 0 \\
0 & 2 \\
0 & 2 \\
2 & 0 \\
0\end{array}$ & 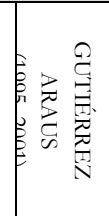 & 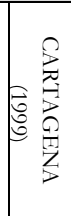 & 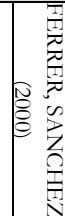 & 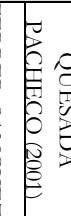 & 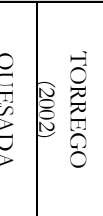 & 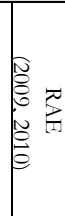 \\
\hline 1 & $\begin{array}{c}\text { Antepresente } \\
\text { Específico }\end{array}$ & + & + & - & + & + & + & + & + & + & + & + & - & + & + & + & + & + & + \\
\hline 2 & $\begin{array}{l}\text { Antepresente } \\
\text { Imediato } \\
\text { (hodierno) }\end{array}$ & & + & - & + & + & + & + & - & + & - & + & + & - & - & - & + & - & + \\
\hline 3 & $\begin{array}{c}\text { Antepresente } \\
\text { Ampliado } \\
\text { (experiencial) }\end{array}$ & - & + & - & - & + & - & - & - & + & - & + & - & - & - & - & + & - & + \\
\hline 4 & $\begin{array}{c}\text { Relevância } \\
\text { Presente }\end{array}$ & - & + & + & + & + & + & + & + & + & + & - & - & + & + & + & + & + & + \\
\hline 5 & Resultativo & - & + & + & + & + & + & + & + & + & - & + & - & + & + & + & + & + & + \\
\hline 6 & Continuidade & - & + & - & - & + & - & - & - & + & - & + & + & + & + & + & + & - & + \\
\hline 7 & $\begin{array}{l}\text { Passado } \\
\text { Absoluto }\end{array}$ & - & - & + & + & . & + & + & + & - & - & - & - & + & + & + & - & + & + \\
\hline 8 & Antepretérito & - & - & - & - & - & - & - & - & - & - & - & - & - & + & + & - & - & - \\
\hline 9 & Prospectivo & - & + & - & - & - & - & & + & - & - & + & - & - & + & + & - & + & + \\
\hline
\end{tabular}

Quadro 2: Dos valores atribuídos ao PC pela norma gramatical.

No entanto, conforme nos alerta o quadro 2, entre os muitos valores associáveis à forma do pretérito perfecto compuesto (PC), também se destaca o sentido de passado absoluto - identificado por parte das gramáticas consultadas. Vejamos alguns casos a seguir:

(3) [...] ustedes saben cuando yo me hice cargo del PAMI, hace aproximadamente un ano y medio, [...] yo he recibido el padrón de seis mil afiliados y a la fecha tenemos un padrón de ciento treinta mil afiliados $<\mathrm{T} 5\rangle$.

(4) Hace tres años que se ha muerto mi padre. (TORREGO, 2002, p.150)

Nos enunciados, os marcadores temporais "hace aproximadamente un año y medio" $\mathrm{e}$ "hace tres años" mostram-nos que a situação descrita não ocorreu dentro do âmbito 
primário de coexistência, mas no âmbito primário de anterioridade. Indicando-nos, por isso, que aparentemente o PC sofre uma mudança no que diz respeito ao tempus. Assim, analisando os exemplos sob a perspectiva reichenbachiana, teríamos situações que ocorrem no âmbito de referência passada ("hace aproximadamente un año y medio" e "hace tres años"), expressando, portanto, o valor de passado absoluto (ME,MR-MF), tal como observamos na figura 4.

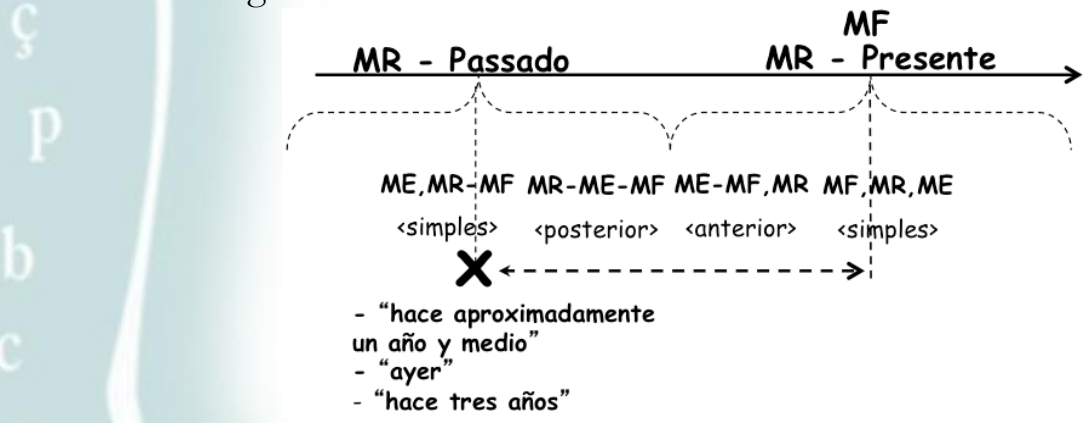

Figura 4: Do valor de passado absoluto sob a perspectiva reichenbachiana

Em poucas palavras, a observação da categoria do tempus no uso da forma verbal com o valor de passado absoluto mostra-nos o pretérito perfecto compuesto aproximando-se do valor fundamental atribuído ao pretérito perfecto simple (PS).

\subsection{OS PRETÉRITOS NAS VARIEDADES DIATÓPICAS ARGENTINAS}

Os maiores esforços investigativos que versaram sobre o comportamento das formas do pretérito perfecto na Argentina desenvolveram-se tendo em vista, fundamentalmente, as variedades bonaerense e noroeste - região onde se localiza San Miguel de Tucumán. A figura 5 identifica as duas zonas no território argentino. Além disso, é possível ainda subdividir esses trabalhos em dois tipos de abordagens: (i) uma preocupada exclusivamente com a norma linguística de alguma(s) das regiões argentinas e (ii) outra interessada em descrever a manifestação das formas do pretérito perfecto na América e que, para isso, apresenta brevemente a situação dos pretéritos na Argentina. Essa abrangência investigativa se deve ao uso variado das formas do pretérito perfecto simple e compuesto nas variedades diatópicas do espanhol. 


\section{Revista

$(2)$

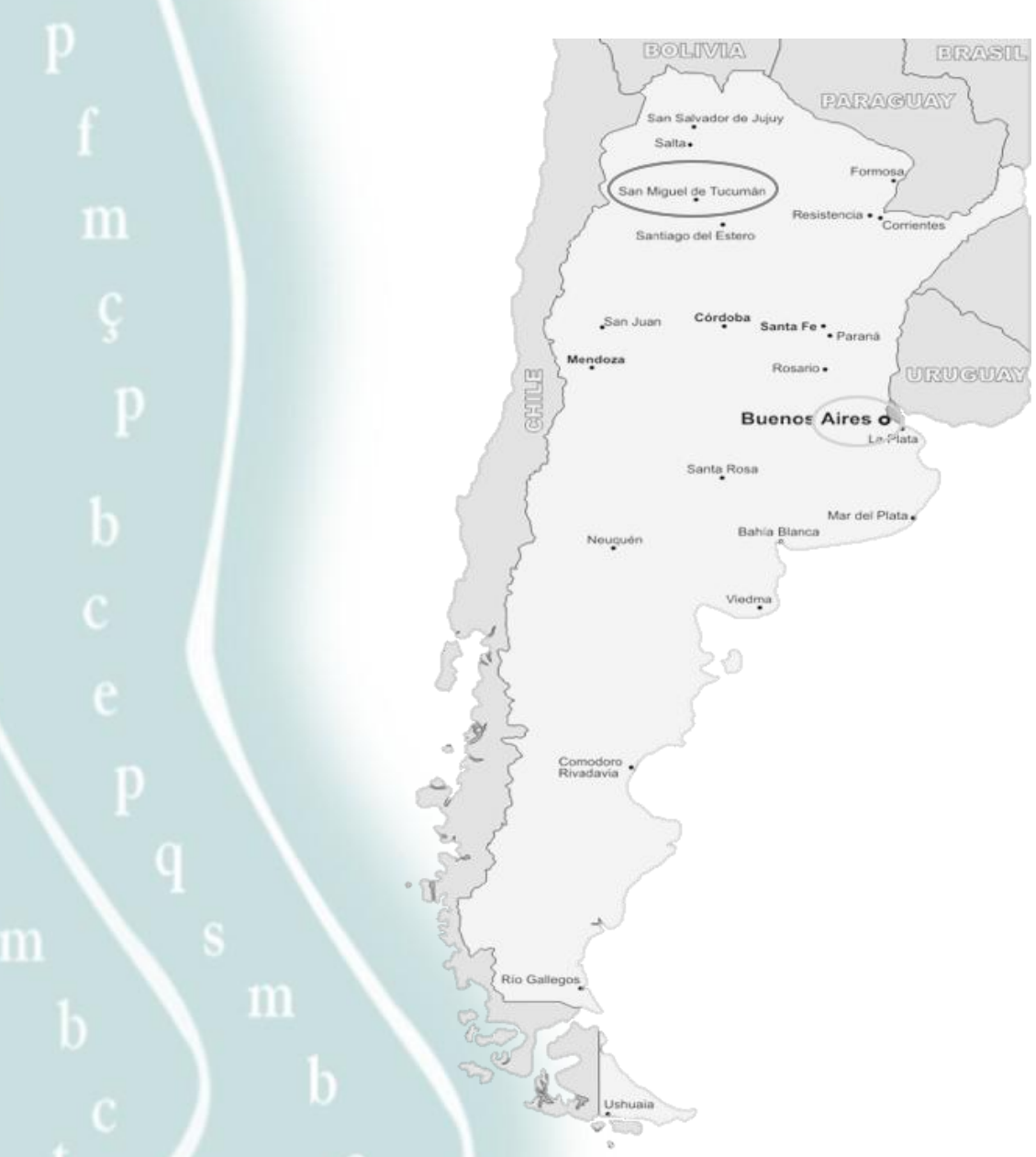

Figura 5: Da localização geográfica de Buenos Aires e San Miguel de Tucumán

Fonte: espanol.mapsofworld.com - com edição nossa.

Atentando-nos inicialmente a essa última abordagem, observamos que trabalhos como os de RAE (1986), Lamiquiz Ibañez (1969), Moreno Fernández (2000) e Oliveira (2007) afirmam a existência de um uso comum para todo o país - no qual predomina a forma do PS. Tanto é assim que lemos, por exemplo, que:

[...] apesar de que a segunda forma [PPC] tenda a desaparecer em benefício da primeira [PPS], especialmente entre falantes de algumas regiões hispano-americanas, como na Argentina (LAMIQUIZ IBAÑEZ, 1969, p.261) ${ }^{8}$.

[...] na Argentina há maior disparidade entre o uso das duas formas verbais. Nesse país, a forma he visto corresponde a $4,7 \%$ das 235 ocorrências do pretérito perfecto, e vi corresponde a 95, 3\%. (OLIVEIRA, 2007, p.63).

8 Original: "[...] a pesar de que la segunda forma [PPC] tienda a desaparecer en beneficio de la primera [PPS], especialmente en hablantes de algunas regiones hispanoamericanas, como en Argentina” (LAMIQUIZ IBAÑEZ, 1969, p.261). 
Como demonstrarão os dados finais desta análise, a conclusão tida pelos autores sobre o comportamento do pretérito perfecto parece decorrer da generalização do uso observado na norma bonaerense às demais variedades diatópicas do país. Por outro lado, uma segunda postura, que opõe o comportamento do PC na região noroeste/norte ao comportamento na região bonaerense, pode ser observada em trabalhos desenvolvidos por Kany (1970), Gutiérrez Araus (2001), Alarcos Llorach (2005) e Jara Yupanqui (2009), dentre os quais retiramos, a título de exemplo, as seguintes asseverações:

[...] o panorama de uso das formas canté/he cantado nesse grande país é variado e aparecem duas zonas claramente diferenciadas em relação ao assunto: por um lado, o norte do país: Tucumán, Salta, etc. e, por outra parte, Buenos Aires e o Litoral (GUTIÉRREZ ARAUS, $2001, \mathrm{~s} / \mathrm{n})^{9}$.

[...] os estudos sobre o espanhol argentino mostram duas tendências. De um lado, a variedade do Rio da Prata [...]. De outro lado, a variedade do noroeste argentino (JARA YUPANQUI, 2009, p.270) ${ }^{10}$.

Soma-se a essa proposta de bipartição a observação do maior índice de ocorrência do PS sobre o PC na área do Río de la Plata. Baseando-se no estudo de Kubarth (1992), Gutiérrez Araus (2001) faz-nos saber que, apesar da significativa diminuição do uso do PC em Buenos Aires, ainda trata-se de uma forma viva nessa zona. Contudo, considerase que já

[...] não funciona como forma de anterioridade imediata à enunciação ou antepresente, como também não se emprega em momentos culminantes ou emotivos da narração ou com valor enfatizador, no entanto, sim, se emprega como forma de valor resultativo com relevância no presente (GUTIÉRREZ ARAUS, 2001, s/n) ${ }^{11}$.

Sobre o noroeste, por outro lado, os quatro autores destacam a maior incidência do PC expressando, inclusive, o valor temporal de PA. Isso é o que também afirma a Nueva Gramática de la Lengua Española (RAE, 2009), manual que ainda assinala o uso da forma composta expressando passado absoluto e relevância presente no noroeste do país. Do mesmo modo, entrevistas sobre crenças e atitudes realizadas com falantes da Argentina indicaram-nos que o valor de PA junto ao PC poderia ser verificado até mesmo na província de Córdoba (ARAUJO, 2009) - área mais central do país.

A pesquisa de Vidal de Battini (1964), destinada à descrição da língua espanhola empregada exclusivamente na Argentina, aporta-nos algumas informações não apresentadas nos estudos já expostos, isso porque, segundo a autora,

9 Original: "[...] el panorama de uso de las formas canté/ he cantado en este gran país es variado y aparecen dos zonas claramente diferenciadas al respecto: por un lado el norte del pais: Tucumán, Salta, etc. y por otra parte, Buenos Aires y el Litoral' (GUTIÉRREZ ARAUS, 2001, s/n).

10 Original: "[...] los estudios sobre el español argentino muestran dos tendencias. De un lado, la variedad del Río de la Plata [...]. De otro lado, la variedad del noroeste argentino" (JARA YUPANQUI, 2009, p.270).

11 Original: "[...] no funciona como forma de anterioridad inmediata a la enunciación o antepresente, como tampoco se emplea en momentos culminantes o emotivos de la narración o enfatizador, sin embargo sí se emplea como forma resultativa con relevancia del presente" (GUTIÉRREZ ARAUS, 2001, s/n). 
$\mathrm{Na}$ fala do país não há diferenças de sentido entre o pretérito (simple) e o perfecto (compuesto), mas sim, há preferências regionais. Há preferência marcada pelo uso do pretérito perfecto na região Noroeste, particularmente a partir de Tucumán até a fronteira com a Bolivia [...]. No resto do país, e particularmente na grande zona de influência de Buenos Aires, preferem-se as formas do pretérito (simple) [...]. Na região central, as duas formas alternam-se [...] com maior tendência às formas simples (VIDAL DE BATTINI, 1964, p.189) ${ }^{12}$.

Em outras palavras, conforme aponta o trabalho levado a cabo nos anos 60 , deveríamos observar no espanhol da Argentina (i) uma igualdade do sentido expresso pelo PS e pelo PC, conformando, portanto, uma variável linguística ao longo de todo território; (ii) a preferência regional pelo uso de uma ou outra variante; (iii) a existência de três padrões de uso, ou seja, além dos dois já conhecidos, haveria um terceiro verificável na região central - tida como zona de transição. Por outro lado, apesar dessas informações distribucionais, notamos no trabalho de Vidal de Battini (1964) a carência da informação sobre qual é o sentido que ambas as formas promulgam, supostamente, da mesma maneira.

Também procurando estabelecer um panorama de uso do PC/PS em toda a Argentina, Múgica (2007) se mostra defensora da tese de que ambas as formas compartilham exatamente o mesmo significado e que, por isso, deveriam ser tratadas como variantes cuja intensificação de uso seria determinada pela norma presente em cada uma das regiões diatópicas do país. Nas palavras da autora:

[...] a distinção perfecto simple/perfecto compuesto não apresenta diferenças de significado. Se nos falantes particulares alteram, tratar-se-ia verdadeiramente de uma variação já que não aportariam diferenças de significado. Mas com diferenças de região a região, no mapa da Argentina, se escolhe um ou outro (MÚGICA, 2007, p.19) ${ }^{13}$.

Conforme objetivamos neste trabalho,

os resultados de nossa análise deverá avaliar essas descrições, corrigindo ou reafirmando as afirmações apresentadas pela tradição investigativa. Em especial, deverá também fornecer maiores detalhes sobre a dimensão da variação entre as formas do pretérito perfecto, posto que nos interessa o conhecimento dos fatores linguísticos e extralinguísticos operantes no uso das duas formas do pretérito perfecto.

\footnotetext{
12 Original: En el habla del país no hay diferencias de sentido entre el pretérito (simple) y el perfecto (compuesto), pero sí hay preferencias regionales. Hay marcada preferencia por el uso del pretérito perfecto en la región Noroeste, particularmente desde Tucumán hacia el límite con Bolivia [...]. En el resto del país, y particularmente en la gran zona de influencia de Buenos Aires, se prefieren las formas del pretérito (simple) $[. .$.$] . En la región central alternan las dos formas [...] con mayor tendencia a las formas simples (VIDAL DE BATTINI,$ 1964, p, 189).

13 Original: [...] la distinción perfecto simple/perfecto compuesto no arroja diferencias de significado. Si en los hablantes particulares alternaran, se trataría verdaderamente de una variación ya que no aportarian diferencias de significado. Pero con diferencias de región a región, en el mapa de la Argentina, se elige uno u otro (MÚGICA, 2007, p.19).
} 


\section{ASPECTOS METODOLÓGICOS PARA O ESTUDO DA EXPRESSÃO DO PA}

\subsection{O CORPUS DE ANÁLISE}

A fim de descrever o modo como as duas variedades argentinas se valem das formas do pretérito perfecto para expressar o valor de passado absoluto compilamos um corpus constituído por enunciados coletados de entrevistas radiofônicas. A escolha por esse gênero discursivo se deveu a que, além de encontrarmos esses enunciados disponíveis na rede mundial de computadores - em rádios das regiões diatópicas, que disponibilizam sua transmissão on-line -, esse gênero apresenta um uso mais próximo ao vernáculo. Uma vez que enunciados de um único gênero não podem constituir um corpus representativo da totalidade de usos linguísticos de uma comunidade de fala, reconhecemos que as apreciações e conclusões provenientes deste estudo estão limitadas a um importante âmbito da língua empregada nas variedades diatópicas avaliadas, no qual se observa o domínio da oralidade com pouco monitoramento.

Posto que obter as informações referentes aos indivíduos que participam da construção dos enunciados e de seu entorno de enunciação é imprescindível para um estudo que se orienta pelos pressupostos da Sociolinguística, destacamos que a opção por esse gênero e o apoio da internet nos possibilitam o acesso a esse tipo de dados - ora por inferência na própria entrevista, ora por contato direto com as rádios ou, até mesmo, por meio de rede sociais. Sobre a obtenção dos áudios, quando não disponibilizados para download pelo próprio site da rádio, o uso do software Audacity 1.3 serviu-nos para gravação das entrevistas. O quadro 3 relaciona as regiões com informações das entrevistas.

\begin{tabular}{|c|c|c|c|c|c|c|c|c|c|}
\hline $\begin{array}{l}\text { Variedade } \\
\text { diatópica }\end{array}$ & Rádio & Programa & $\begin{array}{l}\mathbf{N}^{\circ} \text { de } \\
\text { entrev }\end{array}$ & $\begin{array}{c}\text { Tempo de } \\
\text { grav. }\end{array}$ & $\begin{array}{l}N^{\circ} \text { de } \\
\text { palav. }\end{array}$ & $\begin{array}{l}\mathbf{N}^{\circ} \\
\mathbf{P P}\end{array}$ & $\begin{array}{c}\mathbf{N}^{a} \\
\text { infor }\end{array}$ & $\begin{array}{l}\text { Faixa } \\
\text { etária }\end{array}$ & Mulher \\
\hline \multirow{5}{*}{ Buenos Aires } & Continental & La mañana & \multirow{5}{*}{8} & \multirow{5}{*}{$2 \mathrm{~h} 01^{\prime} 30^{\prime \prime}$} & \multirow{5}{*}{21.124} & \multirow{5}{*}{562} & \multirow{5}{*}{16} & \multirow{5}{*}{$28-70$} & \multirow{5}{*}{4} \\
\hline & \multirow{2}{*}{ Palermo } & Comunas en Plural & & & & & & & \\
\hline & & Entre nosotras & & & & & & & \\
\hline & & El vermucito del domingo & & & & & & & \\
\hline & Cooperativa & Los más grandes & & & & & & & \\
\hline \multirow{4}{*}{ S. M. Tucumán } & LV 12 & Manyines en la radio & \multirow{4}{*}{9} & \multirow{4}{*}{$2 \mathrm{~h} 00 ’ 57 ”$} & \multirow{4}{*}{21.221} & \multirow{4}{*}{473} & \multirow{4}{*}{12} & \multirow{4}{*}{$30-59$} & \multirow{4}{*}{4} \\
\hline & \multirow{2}{*}{ LV 7} & La mañana de LV7 & & & & & & & \\
\hline & & La tarde de LV7 & & & & & & & \\
\hline & Fish & Sin pescado concebido & & & & & & & \\
\hline Total & & & 17 & 4h02'27' & 42.345 & 1035 & 28 & $28-70$ & 8 \\
\hline
\end{tabular}

Quadro 3: Da descrição das entrevistas radiofônicas que compõem o corpus

As mais de 4 horas de gravações (Tempo de grav.) referentes às 17 entrevistas radiofônicas $\left(\mathrm{N}^{\mathrm{o}}\right.$ de entrev.) forneceram-nos mais de 42 mil palavras, sendo, em média, mais de vinte e um mil a quantidade de palavras provenientes de cada uma das variedades diatópicas. Em relação à recorrência das formas linguísticas que esperamos encontrar, observam-se 1035 formas do pretérito perfecto ao longo de todo o corpus ( $\mathrm{N}^{\circ}$ de PP). Contudo, recordamos que, por nos interessarmos exclusivamente pelas formas verbais que ocorrem no contexto de PA, nem todas as 1035 ocorrências serão analisadas neste 


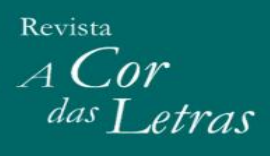

Feira de Santana, v. 19, n. Especial Dossiê: VII Encontro de Sociolinguística, p. 154-179, março de 2018

estudo, apenas as formas que se alinham ao âmbito temporal delimitado, isto é, apenas os 599 casos do pretérito perfecto (Tabela 1).

\begin{tabular}{|c|c|c|c|c|c|c|c|c|c|c|}
\hline \multirow{3}{*}{$\frac{111}{\text { Buenos Aires }}$} & \multicolumn{6}{|c|}{ ANTEPRESENTE } & \multirow{2}{*}{\multicolumn{2}{|c|}{$\begin{array}{l}\text { PASSADO } \\
\text { ABSOLUTO }\end{array}$}} & \multirow{2}{*}{\multicolumn{2}{|c|}{ TOTAL }} \\
\hline & \multicolumn{2}{|c|}{ Imediato } & \multicolumn{2}{|c|}{ Específico } & \multicolumn{2}{|c|}{ Ampliado } & & & & \\
\hline & 42 & $30 \%$ & 83 & $26 \%$ & 74 & $29 \%$ & 352 & $40 \%$ & 551 & $35 \%$ \\
\hline Tucumán & 59 & $43 \%$ & 112 & $35 \%$ & 47 & $19 \%$ & 247 & $28 \%$ & 465 & $29 \%$ \\
\hline Total & 101 & $100 \%$ & 195 & $100 \%$ & 121 & $100 \%$ & 599 & $100 \%$ & 1016 & $100 \%$ \\
\hline
\end{tabular}

Tabela 1: Da totalidade de dados por âmbito temporal ${ }^{14}$

\subsection{O GOLDVARB YOSEMITE}

Uma vez que nos propomos a desenvolver uma análise multivariada, que, como tal, investiga "situações em que a variável linguística em estudo é influenciada por vários elementos do contexto, ou seja, múltiplas variáveis independentes" (GUY; ZILLES, 2007, p. 105), faz-se pertinente recorrer a um método estatístico que nos permita avaliar e comparar quantitativamente os diferentes efeitos dos fatores contextuais, bem como detectar e medir tendências que esclareçam a variação linguística (TAGLIAMONTE, 2006, p. 72). Repousa sobre essa abordagem o pressuposto de que, ao usar a língua, os falantes fazem escolhas, que se definem como formas alternativas discretas com o mesmo valor referencial ou função gramatical (WEINREICH; LABOV; HERZOG, 2006 [1968]). Uma vez que essas escolhas variam sistematicamente (heterogeneidade ordenada), podem ser descritas quantitativamente. Assim, a análise que buscamos neste estudo visa avaliar os efeitos de alguns fatores linguísticos e extralinguísticos sobre as ocorrências das formas que constituem a variável que está sendo tratada como dependente, isto é, o PC e o PS. Os grupos de fatores analisados são (i) marcador temporal, (ii) forma base do verbo, (iii) sujeito, (iv) complemento verbal, (v) tipo de oração, (vi) origem diatópica, (vii) gênero/sexo, (viii) idade.

Com tal propósito, recorremos ao software Goldvarb Yosemite (SANKOFF; TAGLIAMONTE; SMITH, 2015), uma ferramenta utilizada na Sociolinguística Variacionista que calcula regressões logísticas com efeitos fixos. Por se tratar de uma análise voltada à variação linguística, recorremos ao software apenas em contextos em que efetivamente se observa o fenômeno da variação.

Diante de todos os dados gerados, o Goldvarb Yosemite auxiliar o pesquisador na avaliação e seleção dos grupos de fatores considerados estatisticamente significantes para a compreensão do comportamento do fenômeno variável. Uma vez que os dados não selecionados - de menor significância estatística - também podem nos servir como argumento em nossa discussão (TAGLIAMONTE, 2006, p.237; GUY, ZILLES, 2007, p.215), apresentaremos, entre colchetes, os pesos relativos dos fatores não selecionados pelo Goldvarb Yosemite.

\footnotetext{
14 A discrepância do número total de ocorrências de formas do pretérito perfecto entre o quadro 1 e a tabela 1 deve-se a retirada, daquele quadro, dos 19 casos que fogem aos âmbitos temporais de antepresente e passado absoluto.
} 


\section{Revista \\ ACor \\ das I etras}

Alertamos que, para a determinação de alguns dos dados fornecidos pelo Goldvarb Yosemite, o software nos exige a prévia seleção de uma das variantes dependentes para proceder à análise. Nossa opção foi pela forma composta, haja vista que vem se revelando historicamente como uma forma verbal dinâmica e mutável (TAGLIAMONTE, 2012, p. 298), que ocasiona, consequentemente, o rearranjo no funcionamento do PS, ao longo do tempo"

\section{A EXPRESSÃO DO PA EM VARIEDADES ARGENTINAS}

\subsection{O PASSADO ABSOLUTO EM BUENOS AIRES}

A tabela 2 sintetiza a análise dos dados encontrados no contexto de passado absoluto no corpus compilado de Buenos Aires. Ao fim da tabela, dispomos os valores de input e log-likelihood, além da quantidade e do percentual gerais de ocorrências do PC (8 casos $/ 2 \%$ ) na relação com o total de casos do pretérito perfecto (352 casos).

\begin{tabular}{|c|c|c|c|c|c|}
\hline \multicolumn{4}{|c|}{ GRUPOS DE FATORES } & $\% \mathrm{PC}$ & Peso \\
\hline \multirow{22}{*}{ 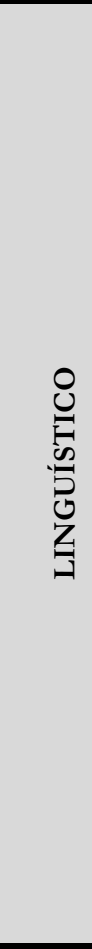 } & \multirow{4}{*}{$\begin{array}{l}\text { MARCADORES } \\
\text { TEMPORAIS }\end{array}$} & \multirow{2}{*}{ Tipo } & Tempo & $3 \%$ & - \\
\hline & & & Durativo & $0 \%$ & - \\
\hline & & \multirow{2}{*}{ Presença } & Explícito & $3 \%$ & [.59] \\
\hline & & & Implícito & $1 \%$ & [.41] \\
\hline & \multirow{8}{*}{$\begin{array}{l}\text { FORMA BASE } \\
\text { DO VERBO }\end{array}$} & \multirow{2}{*}{ Telicidade } & Télico & $3 \%$ & - \\
\hline & & & Atélico & $0 \%$ & - \\
\hline & & \multirow{2}{*}{ Duração } & Pontual & $4 \%$ & {$[.52]$} \\
\hline & & & Durativo & $1 \%$ & {$[.49]$} \\
\hline & & \multirow{4}{*}{ Modo de ação } & Achievement & $4 \%$ & {$[.59]$} \\
\hline & & & Accomplishment & $3 \%$ & {$[.42]$} \\
\hline & & & Atividade & $0 \%$ & - \\
\hline & & & Estado & $0 \%$ & - \\
\hline & \multirow{5}{*}{ SUJEITO } & \multirow{3}{*}{ Pessoa } & $1^{a}$ & $4 \%$ & {$[.46]$} \\
\hline & & & $2^{\mathrm{a}}$ & $7 \%$ & {$[.90]$} \\
\hline & & & $3^{\mathbf{a}}$ & $1 \%$ & {$[.47]$} \\
\hline & & \multirow{2}{*}{ Número } & Singular & $1 \%$ & .39 \\
\hline & & & Plural & $7 \%$ & .81 \\
\hline & \multirow{2}{*}{$\begin{array}{c}\text { COMPLEMENTO } \\
\text { VERBAL }\end{array}$} & \multirow{2}{*}{ Número } & Singular & $5 \%$ & [.49] \\
\hline & & & Plural & $7 \%$ & {$[.56]$} \\
\hline & \multirow{3}{*}{ ORAÇÃO } & \multirow{3}{*}{ Tipo } & Afirmativa & $3 \%$ & - \\
\hline & & & Negativa & $0 \%$ & - \\
\hline & & & Interrogativa & $0 \%$ & - \\
\hline \multirow{5}{*}{ 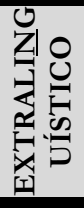 } & \multirow{2}{*}{ SEXO } & \multicolumn{2}{|c|}{ Masculino } & $2 \%$ & {$[.50]$} \\
\hline & & \multicolumn{2}{|c|}{ Feminino } & $2 \%$ & {$[.51]$} \\
\hline & \multirow{3}{*}{ IDADE } & \multicolumn{2}{|c|}{ Até 35 anos } & $0 \%$ & - \\
\hline & & \multirow{2}{*}{\multicolumn{2}{|c|}{$36-55$ anos }} & $3 \%$ & {$[.55]$} \\
\hline & & & & $1 \%$ & {$[.33]$} \\
\hline \multicolumn{4}{|c|}{ Input: .08 } & \multicolumn{2}{|c|}{ Total N=8/352 (2\%) } \\
\hline
\end{tabular}


Tabela 2: Da análise multivariada na expressão do passado absoluto em Buenos Aires ${ }^{15}$

Tendo em vista que o uso quase categórico do PS (98\%) nesse contexto de análise implica uma sobreposição massiva da forma simples sobre o uso do PC (2\%) - tanto de modo geral, como no exame de cada um dos fatores envolvidos na análise multivariada a discussão seguinte irá se restringir apenas em apontar os fatores que, de alguma maneira, contribuem para que a forma composta ainda mantenha uma ocorrência, mesmo que discreta.

Assim, a análise multivariada que, no passado absoluto, o PC é mais recorrente em contextos com uma leitura perfectiva. Conforme se observa no gráfico 1, o PC tem o uso concentrado junto a marcadores temporais sem informação aspectual de duração (3\%) e a verbos télicos $(3 \%)$ - do tipo accomplishment (3\%) ou achievement (4\%). Também se identifica um percentual maior do PC junto a verbos pontuais (4\%).

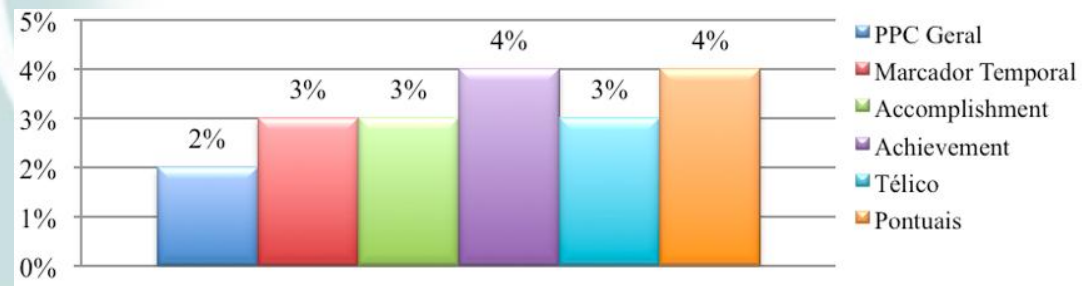

Gráfico 1: Da incidência percentual dos grupos de fatores que favorecem a leitura de perfectividade no âmbito de passado absoluto, segundo os dados de Buenos Aires

A fim de melhor avaliar esses dados, expomos, a seguir, os enunciados encontrados nesse contexto de análise:

(5) Mi labor específica y la labor de mi grupo es llevar dignidad, por ejemplo, como lo hemos hecho el domingo pasado, en el anfiteatro del parque Centenario $[\ldots]<\mathrm{B} 1>$.

(6) Hace unos días atrás hemos recibido, desde la legislatura porteña [...] una invitación a un recital por el monumento a la mujer originaria. [...] Que se realizó el sábado, veinticinco de septiembre, en diagonal sur y Perú $<\mathrm{B} 2>$.

(7) [...] esto ha generado en su momento mucha polémica. A ver, yo entiendo que a una figura como la de Roca se le apremia con el billete más caro o de más valor en nuestro país ¿no? Eh... con los cien pesos. Y a otras figuras, como San Martín, se lo ponen en los billetes de cinco ¿no? <B2>

(8) Tati siempre nos dice que es la tarea de los organismos de derechos humanos. Nosotros hemos constituido uno [en diciembre]. El archivo de la memoria de la diversidad sexual. Tienen la tarea de mantener vivo esto, porque si la gente se olvida, mira lo que pasa $<\mathrm{B} 4>$.

(9) Habría que ir por el título de algún profesional que ha dicho esas cosas [en aquella ocasión], porque han violado leyes, diciendo esas mentiras, barbaridades obscurantistas $<\mathrm{B} 4>$.

${ }^{15}$ A análise estatística realizada pelo Goldvarb Yosemite seleciona, entre as diversas rodadas de análise, aquela que apresenta $\mathrm{o}(\mathrm{s})$ grupo(s) de fatores considerado(s) estaticamente relevante(s) para o estudo do fenômeno variável. O peso relativo desses fatores é informado, na tabela, sem o uso de colchetes (“[]"). Contudo, tendo em vista que os dados considerados com menor significância estatística podem nos servir para refutar/refinar uma hipótese (TAGLIAMONTE, 2006; GUY; ZILLES, 2007), também apresentamos o peso relativo dos fatores não selecionados pelo software. Esses valores são apresentados entre colchetes (“[ ]") e foram retirados da primeira rodada "Stepping down" - já que encontramos o menor valor de "log likelihood" nessa rodada. 
(10) Has terminado un estudio... un sondeo, hace poquitos días ¿no? <B5 $>$

(11) $[\ldots]$ hemos dejado una base enorme el año pasado y que ahora le llegaron un montón de jugadores que son de nivel óptimo $<$ B6 $>$.

Observamos nos enunciados (6), (8), (10) e (11) situações ("hemos recibido una invitación", "bemos constituido uno", "has terminado un estudio", "bemos dejado una base enorme", respectivamente) pontuais e télicas (achievement) que não só descrevem ações perfectivas, mas parecem repercutir, de alguma maneira, no momento presente. De modo mais pontual, em (6) o contraste entre o PC ("bemos recibido") e o PS ("realizo") permite observar o enunciador destacar aquilo que lhe confere e que lhe dá lugar de destaque ("receber o convide do próprio poder legislativo"), daquilo que objetivamente ocorreu no tempo e espaço ("recital pelo monumento à mulher originária").

Na mesma direção, em (8) e (11), os enunciadores parecem enfatizar, por meio da forma composta, que seu trabalho ("bemos constituído uno" e "bemos dejado una base") não apenas é relevante, mas ainda traz consequências ao momento da enunciação. Assim, apresenta, de maneira explícita, qual é o resultado presente de sua intervenção no passado ("mantener vivo" e "le llegaron un montón de jugadores"). Em especial, em (11), observa-se mais uma vez a contribuição da oposição entre PS e PC para a argumentação desenvolvida pelo enunciador, de maneira que, com o PC ("hemos dejado"), trata-se como especialmente relevante a ação realizada por ele e, com o PS (“llegaron”), apresenta-se o resultado, mais recente, da situação previamente desenvolvida.

Finalmente, em (10), parece ser possível inferir, com o uso da forma composta ("has terminado"), a valoração de uma informação nova, a qual deve contribuir para um maior esclarecimento sobre o posicionamento do eleitorado sobre o cenário político em discussão.

Nesse ponto, é valido estabelecer também um paralelo com os dados relativos ao estudo da interferência das pessoas gramaticais. Conforme expõe a tabela 2, o percentual de uso do PC junto à primeira pessoa é duplicado (4\%), em comparação ao seu percentual geral no âmbito de passado absoluto $(2 \%)$, e mais que triplicado junto à segunda pessoa $(7 \%)$ - significância que é reforçada pelo peso relativo atribuído a esse fator [.90]. Apesar da pouca quantidade de dados que viabilizam a análise do fator "pessoa do discurso", esses números, reforçados pela discussão apresentada na análise dos enunciados (6), (8), (10) e (11), parecem indicar a possibilidade de marcar como mais relevante uma situação específica e concreta que foi vivenciada pelo enunciador ou pelo enunciatário. Não obstante, a comprovação desse comportamento requer uma análise mais sistemática e ampliada desse fator, em estudos futuros.

Voltando-nos ao estudo das informações pertencentes à base verbal, observamos que, devido ao valor de duração que os verbos de accomplishment também apresentam, verifica-se a presença discreta desse valor nos enunciados (5), (7) e (9), já que “bacer algo", "generar mucha polémica", "decir esas cosas" - respectivamente -, demandam certo período de desenvolvimento antes de chegar a sua conclusão. Apesar dessa característica, é importante também destacar que se soma aos verbos de accomplishment o traço de "telicidade", o que nos permite observar as referidas ações como perfectivas, isto é, terminadas. Em complemento, a exclusiva recorrência de marcadores temporais de 
passado, sem informação durativa, corrobora a leitura perfectiva identificada, de modo geral, nos dados expostos.

Dentre os fatores que favorecem a construção do valor de duração, apenas o relativo ao número do sujeito $(7 \%)$ - grupo de fatores selecionado - e do complemento verbal $(7 \%)$ apresenta um discreto incremento percentual no uso do PC. A observação desses fatores, por exemplo, no enunciado (9) mostra que, aliados a um verbo télico e pontual - como é o caso de "violar" -, favorecem uma leitura iterativa, segundo a qual entendemos que o desrespeito a diferentes leis por vários profissionais foi realizado muitas vezes no passado descrito.

Tendo em vista que é possível encontrar na norma bonaerense o uso do PC também fazendo referências a situações genéricas ocorridas em um passado menos preciso/determinado (RODRÍGUEZ LOURO, 2009, 2011), os dados encontrados do PC parecem indicar que esse comportamento não é tão evidente no contexto de passado absoluto, posto que, com exceção do enunciado (9), as demais ocorrências do PC fazem referência a fatos pontuais efetivamente identificados pelo enunciador ("lo hemos hecho", "hemos recibido una invitación", "ha generado mucha polémica", "hemos constituido uno", "has terminado un estudio", "bemos dejado una base") como pertencente a um momento definido do passado ("el domingo pasado", "bace unos días atrás", "en su momento", "en diciembre", "bace poquitos días").

Contudo, a observação do enunciado (9) revela que o uso do PC fazendo referência a situações genéricas em uma envoltura temporal menos definida ocorre justamente em um contexto linguístico em que o sujeito é menos determinado. Tanto é que, no enunciado (9), ele é modificado por um adjetivo indefinido (“algún”) ou está ausente - em um verbo conjugado na terceira pessoa do plural e com o agente indeterminado ("han violado leyes"). Ademais, a soma de um complemento verbal plural corrobora a imprecisão informativa ("esas cosas/leyes"), pois não se sabe exatamente o número de vezes ou quando as coisas foram ditas/leis foram violadas.

Dirigindo-nos ao estudo dos grupos de fatores extralinguísticos, aparentemente, a análise do gênero/sexo dos falantes apresenta um padrão equilibrado do uso do PC nos dados coletados de Buenos Aires - tanto é assim que o percentual e peso relativo atribuído a ambos os gêneros/sexos são praticamente iguais ${ }^{16}$. Por sua vez, o estudo da faixa-etária aponta que a forma composta apresenta um padrão de uso mais conservador, posto que não é encontrado entre os mais jovens, sendo que os poucos dados se concentram entre falantes de idade entre 36 e 55 anos - grupo seguido pelos mais velhos (maiores de 55 anos).

Em suma, o estudo do PC no âmbito de PA em Buenos Aires revela que essa forma é discretamente mais recorrente junto a traços linguísticos que operam na construção de situações perfectivas. Característica que, em combinação com o percentual mais elevado na primeira e segunda pessoas do discurso, parece indicar um uso com valor de relevância presente. Além disso, é provável que a referenciação a situações genéricas ocorridas em um passado menos definido também se realize por meio do uso do PC -

16 Devido à limitação de nossos dados em equiparar sistematicamente a quantidade de informantes de ambos os gêneros/sexos, as informações aferidas requerem uma avaliação futura mais estendida. 
sobretudo quando junto a traços que favorecem a descrição situações menos definidas, tais como a marcação de plural e marcadores de tempo indeterminado. Sobre o aspecto extralinguístico, os dados apontam um uso mais recorrente do PC entre os mais velhos. Uma vez que o PS apresenta um uso quase que categórico nesse contexto temporal e que os jovens recorrem apenas a ele para expressar o $\mathrm{PA}$, parece haver uma tendência à intensificação do desuso do PC nesse âmbito.

A expressiva recorrência da forma simples em todos os cenários contemplados pelas variáveis independentes e dependentes evidencia não apenas a vitalidade dessa forma em Buenos Aires, mas também seu prestígio na expressão do passado absoluto.

\subsection{O PASSADO ABSOLUTO EM SAN MIGUEL DE TUCUMÁN}

\begin{tabular}{|c|c|c|c|c|c|}
\hline \multicolumn{4}{|c|}{ GRUPOS DE FATORES } & $\%$ PC & Peso \\
\hline \multirow{5}{*}{\multicolumn{2}{|c|}{$\begin{array}{l}\text { MARCADORES } \\
\text { TEMPORAIS }\end{array}$}} & \multirow{3}{*}{ Tipo } & Tempo & $13 \%$ & {$[.53]$} \\
\hline & & & Durativo & $6 \%$ & {$[.31]$} \\
\hline & & & Indeterminado & $0 \%$ & - \\
\hline & & \multirow{2}{*}{ Presença } & Explícito & $13 \%$ & {$[.54]$} \\
\hline & & & Implícito & $10 \%$ & {$[.48]$} \\
\hline \multirow{8}{*}{ 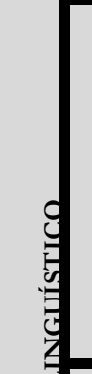 } & \multirow{8}{*}{$\begin{array}{l}\text { FORMA BASE } \\
\text { DO VERBO }\end{array}$} & \multirow{2}{*}{ Telicidade } & Télico & $9 \%$ & {$[.49]$} \\
\hline & & & Atélico & $16 \%$ & {$[.51]$} \\
\hline & & \multirow{2}{*}{ Duração } & Pontual & $9 \%$ & {$[.50]$} \\
\hline & & & Durativo & $13 \%$ & {$[.50]$} \\
\hline & & \multirow{4}{*}{$\begin{array}{l}\text { Modo de } \\
\text { ação }\end{array}$} & Achievement & $9 \%$ & {$[.44]$} \\
\hline & & & $\begin{array}{c}\text { Accomplishme } \\
\text { nt }\end{array}$ & $10 \%$ & {$[.50]$} \\
\hline & & & Atividade & $12 \%$ & {$[.48]$} \\
\hline & & & Estado & $17 \%$ & {$[.60]$} \\
\hline & \multirow{5}{*}{ SUJEITO } & \multirow{3}{*}{ Pessoa } & $1^{\mathrm{a}}$ & $7 \%$ & {$[.41]$} \\
\hline & & & $2^{\mathrm{a}}$ & $22 \%$ & {$[.88]$} \\
\hline & & & $3^{\mathrm{a}}$ & $13 \%$ & {$[.53]$} \\
\hline & & \multirow{2}{*}{ Número } & Singular & $10 \%$ & {$[.47]$} \\
\hline & & & Plural & $14 \%$ & {$[.58]$} \\
\hline & \multirow{2}{*}{$\begin{array}{c}\text { COMPLEMENTO } \\
\text { VERBAL }\end{array}$} & \multirow{2}{*}{ Número } & Singular & $11 \%$ & {$[.52]$} \\
\hline & & & Plural & $10 \%$ & {$[.41]$} \\
\hline & \multirow{3}{*}{ ORAÇÃO } & \multirow{3}{*}{ Tipo } & Afirmativa & $12 \%$ & {$[.49]$} \\
\hline & & & Negativa & $15 \%$ & {$[.56]$} \\
\hline & & & Interrogativa & $0 \%$ & - \\
\hline \multirow{5}{*}{ 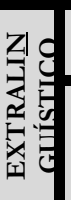 } & \multirow{2}{*}{ SEXO } & \multirow{2}{*}{\multicolumn{2}{|c|}{$\begin{array}{l}\text { Masculino } \\
\text { Feminino }\end{array}$}} & $14 \%$ & - \\
\hline & & & & $0 \%$ & - \\
\hline & \multirow{3}{*}{ IDADE } & \multicolumn{2}{|c|}{ Até 35 anos } & $9 \%$ & .44 \\
\hline & & \multicolumn{2}{|c|}{$36-55$ anos } & $19 \%$ & .64 \\
\hline & & \multicolumn{2}{|c|}{ Mais de 55 anos } & $0 \%$ & - \\
\hline \multicolumn{4}{|c|}{ Input: .13 } & \multicolumn{2}{|c|}{$\begin{array}{c}\text { Total } \mathrm{N}=28 / 247 \\
(11 \%)\end{array}$} \\
\hline
\end{tabular}

Tabela 3: Da análise multivariada na expressão do passado absoluto em San Miguel de Tucumán 
Além do uso maior do PS (89\%) que o do PC nesse contexto, um exame mais cuidadoso dos fatores que exercem influência sobre o uso dessas formas, indica-nos que a forma simples tem seu índice levemente incrementado junto a fatores menos suscetíveis à expressão de duração, especialmente com verbos télicos e pontuais (91\%). Em movimento inverso, apesar da menor recorrência da forma composta junto a marcadores temporais com valor durativo $(6 \%)$, o percentual de uso do PC é levemente favorecido junto a outros traços linguísticos que veiculam a informação de duração, indicando que essa forma verbal também é privilegiada em contextos que favorecem uma leitura de continuidade.

Nessa direção, o gráfico 2 indica o percentual mais elevado de ocorrência do PC junto a verbos atélicos $(16 \%)$ e durativos $(13 \%)$ - especialmente, com os estativos $(17 \%)$ -, bem como junto a sujeito plural $(14 \%)$ e orações negativas $(15 \%)^{17}$.

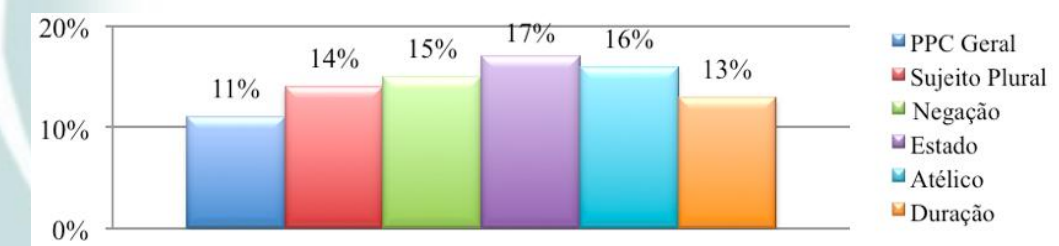

Gráfico 2: Da incidência percentual dos grupos de fatores que favorecem a leitura de continuidade no âmbito de passado absoluto, segundo os dados de San Miguel de Tucumán

Conforme observamos nos enunciados (12) e (13), os verbos de atividade ("han estado haciendo aguante") e estado ("ha sido") - marcados pelos traços de duração e atelicidade - favorecem uma leitura durativa da situação descrita. No entanto, por se inserir em uma perspectiva temporal já concluída no momento de fala, essas situações são vistas em sua completude. Assim, por exemplo, sabemos pelo conhecimento de mundo que dispomos que a torcida ("nos han estado haciendo aguante") descrita em (12) já não está presente.

(12) Besos, chicas. Muy divinas todas que nos han saludado, nos han estado haciendo aguante [en el show del último sábado] $<\mathrm{T} 2>$.

(13) [...] nos vamos a abocar al show del sábado que ha sido espectacular $<$ T2 $>$.

A observação das ocorrências do PC em orações negativas - enunciados (14) e (15) - mostra-nos que, no âmbito de PA, a polaridade aparentemente serve para destacar, em uma relação contrastiva, as implicações de uma situação passada específica no momento de fala. Assim é que em (14), o enunciador B se contrapõe a A ao afirmar, por meio do PC, que não foi fotografado nenhuma vez com "Cecy" ("no se ha sacado"), sentindo-se, por isso, desprestigiado e menos importante quando enuncia.

17 Conforme temos esclarecido, apesar dos fatores que abrem precedentes para uma leitura durativa reiteradamente contribuírem para uma acentuação na recorrência da forma composta, também podemos encontrar o uso do PS junto a eles - inclusive, com maior frequência que o PC em muitas conjunturas de análise. O que merece especial atenção, contudo, é o fato de sistematicamente a forma composta ter uma relativa maior consistência de uso junto a esses traços, enquanto a simples recebe um favorecimento especial junto a fatores menos abertos à leitura continuativa. 
(14) A: ¡Qué lindas que está nuestra foto, Cecy! Nos sacó una foto [el sábado].

B: Conmigo no se ha sacado [el sábado] $<\mathrm{T} 2>$.

(15) Ni yo he nacido hablando bien $<$ T9 $>$.

Na mesma direção, em (15), a entrevistadora discorre sobre o desafio que envolve a formação profissional do jornalista. Com esse fio argumentativo, mostra que, mesmo ocupando atualmente uma profissão (locutora de rádio) em que a voz e a retórica são ferramentas de trabalho importantes, passou por um árduo processo de transformação, de um estado em que não "falava bem", ao estado atual, em que é uma boa comunicadora. Essa transformação é implicada também por meio do uso do PC, posto que, ao ser usada para se referir a uma ação no PA ("he nacido"), evidencia o esforço pessoal em sair do estado inicial de despreparo (quando não era uma boa locutora) para se transformar, por fim, em uma profissional reconhecida.

O uso do PC com função contrastiva em orações negativas parece ser resultante do valor de relevância presente associado ao PC (RODRÍGUEZ LOURO, 2008, p.3), posto que esse uso estabelece relação - ainda que subjetiva - entre situações passadas e o momento de fala. Como vimos, esse sentido se constroi a partir do valor aspectual de perfeito, o qual, segundo Comrie (1976), volta-se ao momento posterior ao da situação descrita, mostrando-nos seus resultados, isto é, a relevância presente de uma situação concluída.

Por sua vez, conforme observamos em (16) e (17) a análise do traço de pluralidade junto ao sujeito permite aferir, em alguns contextos, o maior prolongamento da situação descrita. Assim é que a locomoção de um grupo de pessoas ("la gente que ha ido") e o cumprimento oferecido por todas elas ("me han saludado") demandam naturalmente um maior período para se efetivar. Contudo, percebe-se novamente que, por se inserir em uma perspectiva temporal já concluída no momento de fala (PA), identificamos que, mesmo tomando um maior tempo para se realizar em sua completude, toda a situação descrita encontra-se concluída quando enunciada. Ou seja, não há a possibilidade dessas situações descritas persistirem até o MF.

(16) Gracias a toda la gente que ha ido a Los Arcos a vernos [el sábado] <T1 $>$.

(17) $[. .$.$] dicen que en Leales nos escucha un montón de gente. Han estado y me han saludado$ después del show [del sábado] $<$ T1 $>$.

A análise do grupo de fatores relativo à pessoa gramatical indica um uso percentualmente maior junto à segunda pessoa (22\%/[.88]). Apesar da alto valor de peso relativo, esse dado equivale apenas aos dois casos expostos a seguir. Tendo em vista a maior restrição de dados junto à segunda pessoa, faz-se necessário estender futuramente o estudo a uma análise mais ampliada, sistematizada e focada nesse fator a fim de avaliar sua real contribuição no uso do PC.

(18) Usted, creo, ha vuelto a ser el sexy symbol que era antes del Sábado $<$ T2 $>$.

(19) A: He presentado la renuncia en el día de ayer en forma indeclinable. 
B: [...] usted ha decidido [ayer] esta renuncia porque el grupo menor no estaba de acuerdo con su forma de trabajo $<\mathrm{T} 5>$.

Observando o enunciado (18), em paralelo ao que também observamos em (20) e (21), parece haver uma preferência pela forma composta sempre que esteja em uma oração subordinada substantiva, encabeçada pelo verbo "creer", expressando, portanto, a opinião pessoal do enunciador diante do fato observado por ele.

(20) Creo que [el show de sábado] ha sido el mejor que hemos hecho $<$ T2 $>$.

(21) Yo creo que ustedes mismos han sido el termómetro de lo que ha ocurrido con el cambio prestacional en aquel momento $<\mathrm{T} 5>$.

A relevância desse contexto sintático é tamanha que todas as ocorrências de orações subordinadas aos verbos de opinião ("creer/ pensar") no corpus de San Miguel de Tucumán são da forma composta. Isso permite-nos verificar que, ao expor sua opinião, o enunciador vale-se da forma composta para apresentar uma situação segundo seu ponto de vista. Em complemento, destacamos que esse comportamento da forma composta não é identificado em Buenos Aires.

Finalmente, voltando-nos à análise do PA, um único caso parece escapar a essa tendência descrita. Conforme vericamos em (22), a oração subordinada constroi-se com uma forma simples ("se sentieron"). Apesar da aparente exceção, encontramos logo em seguida o uso da forma composta ("se han detectado"), dessa vez fazendo referência a uma ação que, segundo o enunciador, é presumível (presunta), mais genérica - conforme ressaltam o adjetivo indefinido "algunas" e o complemento plural - e desenvolvida em um passado menos definido. Por outro lado, quando o enunciador assume uma postura mais assertiva e menos modalizada para fazer referência à mesma situação descrita - conforme se lê em (23) -, ele vale-se da foma simples ("dije concretamente que detectaron irregularidades"). Parece, portanto, que a forma composta pode funcionar, nessa variedade diatópica, também com uma espécie de modalizador do discurso, à medida que apresenta um fato como menos concreto e pressumível.

(22) Yo creo que en el fondo se sintieron molestos porque se han detectado algunas irregularidades o presuntas irregularidades en un área del PAMI que se llama Relación con beneficiario <T5 $>$.

(23) Yo lo que dije concretamente que se detectaron irregularidades en un área llamada Relación con Beneficiario $<\mathrm{T} 5>$.

Conduzindo a análise para os fatores extralinguísticos, observamos que os casos encontrados são observados na fala masculina, já que a fala feminina apenas apresenta casos do $\mathrm{PS}^{18}$. Além disso, o estudo da variável idade revela a ausência de casos do PC entre os mais velhos (acima de 55 anos), um uso mais retraído entre menores de 35 anos e uma preferência maior entre adultos de 36 a 55 anos. Juntos, os dois grupos de fatores parecem indicar que o uso da forma composta no contexto de passado absoluto é

18 Devido à limitação do corpus de análise na equalização de falantes de ambos os gênero/sexo, esses dados apenas indicam possíveis tendências, exigindo uma análise mais refinada a fim de comprova-las. 
relativamente recente na variedade tucumana, posto que ainda não é identificado na fala feminina, nem entre os falantes maiores de 55 anos e, por isso, tendendo a um incremento caso se torne bem avaliado socialmente e seja transmitido às gerações vindouras. Contudo, chamamos atenção à evidente maior recorrência, de modo geral, do PS nesse contexto de análise, o que enfatiza o papel singular dessa forma na expressão do passado absoluto.

\section{CONSIDERAÇÕES FINAIS}

Comum às duas variedades diatópicas investigadas neste estudo é a preferência dada, de modo geral, ao PS sobre o PC, quando se trata da expressão do PA. No entanto, a análise multivariada indicou-nos que, conforme a variedade, há especificidades dentro desse padrão geral. Além de um percentual mais elevado de recorrência do PC, San Miguel de Tucumán apresenta um favorecimento dessa forma junto a traços linguísticos que operam na construção do sentido de duração, especialmente junto a verbos atélicos. No que concerne a Buenos Aires, identificamos a ausência do PC junto a verbos atélicos. De maneira que, ao ser favorecido junto a verbos de achievement e accomplishment, os dados de Buenos Aires parecem indicar o uso do PC como marcador de uma situação relevante no presente. Essa mesma função parece ser reforçada na variedade bonaerense pelo uso mais intensificado da forma composta junto à primeira e à segunda pessoas do discurso.

Apesar de não conseguirmos identificar o uso do valor de relevância presente junto às primeira e segunda pessoas na variedade San Miguel de Tucumán, a análise da ocorrência do PC em orações negativas nessa variedade demonstra a possibilidade do uso da forma composta com essa função. Assim, ao invés de favorecer uma leitura de continuidade (como propuseram Schwenter; Cacoullos (2008) e Howe; Rodríguez Louro (2013)), as orações negativas, em associação ao PC, permitem destacar, em uma relação contrastiva, as implicações de uma situação específica passada, no momento de fala.

Em especial, na variedade tucumana, encontramos também o uso intenso da forma composta em orações subordinadas a verbos de opinião, isto é, em contextos de maior posicionamento subjetivo do enunciador sobre um fato descrito. Finalmente, em ambas as variedades, identificamos uma leve tendência a fazer referência a situações genéricas ocorridas em um contexto passado menos definido.

Tudo isso exposto, parece que nas duas variedades diatópicas esconde-se por detrás do uso do PC no âmbito de PA um uso ainda marcado por alguma questão aspectual (duração) ou por uma avaliação subjetiva das situações apresentadas (relevância ou passado genérico). Finalmente, a análise das variáveis extralinguísticas sugere uma contraposição entre as duas variedades, isso porque, em Tucumán identificamos o uso do PC concentrado na fala masculina e o uso do PS, na fala feminina. Em Buenos Aires, por sua vez, o fator gênero/sexo revela uma tendência equilibrada entre homens e mulheres. Novamente, lembramos que os dados referentes ao gênero/sexo apenas nos apontam direcionamentos que demandam futuras investigações a fim de comprová-los ou refutálos

Por sua vez, conforme observamos no gráfico 3, o estudo do fator idade no uso do PC parece indicar que em San Miguel de Tucumán a extensão da forma composta ao 
contexto de PA é um fenômeno mais recente, já que apenas o PS é encontrado entre os maiores de 55 anos, havendo recorrência da forma composta nos dois primeiros grupos etários investigados, com especial destaque para o segundo, com falantes entre 36 e 55 anos. Finalmente, na norma bonaerense, apenas a forma simples é encontrada entre falantes com menos de 35 anos, ao passo que se encontram casos do PC entre falantes maiores de 36 anos. Esse comportamento sugere que o PC caracteriza um uso mais antigo nessa variedade diatópica.

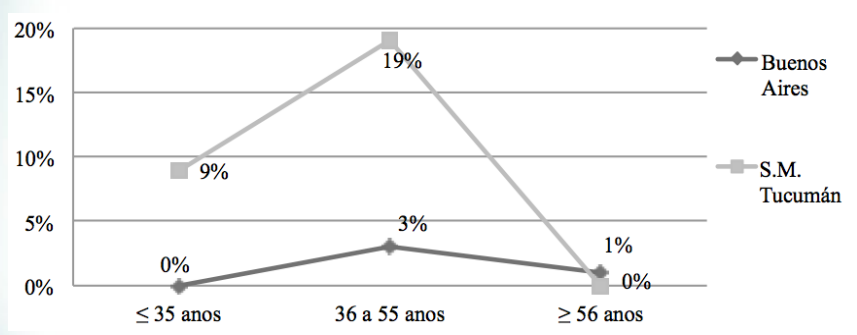

Gráfico 3: Da incidência percentual do grupo de fatores "idade" sobre o uso do PC no âmbito de passado absoluto, nas duas variedades argentinas

Em suma, o PC guarda nas duas variedades traços aspectuais e pragmáticos quando usado no contexto de PA. Em acréscimo, o que nos revela o estudo das variáveis extralinguísticas é que em San Miguel de Tucumán essa forma pode vir a se desenvolver nesse âmbito temporal, estendendo seu uso e, quem sabe, ajustando-se a outros valores. Por outro lado, haja vista a restrição de ocorrências e o uso entre a população mais idosa em Buenos Aires, a história do PC não parece indicar, por hora, uma tendência à extensão e inovação no uso, nessa variedade.

Finalmente, a observação indireta do uso do PS demonstra que, quando se trata da expressão do PA, a forma simples apresenta uma expressiva vitalidade nas duas variedades- sobretudo em Buenos Aires -, tanto é assim que detém um percentual substancialmente maior de ocorrência na análise geral dos dados e no exame pontual de cada um dos fatores. Em San Miguel de Tucumán, identificam-se tanto um uso ligeiramente favorecido entre fatores menos suscetíveis à leitura de duração (verbos télicos e pontuais, por exemplo), como uma tendência, ainda que sutil, a um possível debilitamento futuro de seu emprego, tendo em vista que seu uso é um pouco menor nos dados referentes à população mais jovem.

\section{REFERÊNCIAS}

ALARCOS LLORACH, E. Perfecto simple y compuesto. In: ALARCOS LLORACH, E. Estudios de gramática funcional del español. 3 ed. Madrid: Gredos, 1980. p. 13-49.

ALARCOS LLORACH, E. Gramática de la lengua española. Madrid: Espasa, 2005.

ARAUJO, L S. “La gramática lo propuso, pero he escuchado...": um estudo comparativo sobre o uso dos pretéritos indefinido e perfecto segundo a perspectiva da gramática normativa e a impressão de uso efetivo de hispanofalantes. 
2009. 70 f. Monografia de Conclusão de Curso (Bacharel em Letras) - Faculdade de Ciências e Letras, Universidade Estadual Paulista "Júlio de Mesquita Filho", Araraquara, 2009.

ARAUJO, L. S. O pretérito em espanhol: usos e valores do perfecto compuesto nas regiöes dialetais argentinas. São Paulo: Cultura Acadêmica, 2013.

ARAUJO, L. S. A expressão dos valores "antepresente" e "passado absoluto" no espanhol: Um olhar atento a variedades diatópicas da Argentina e da Espanha. 2017. 410 f. Tese (Doutorado em Linguística e Língua Portuguesa) - Faculdade de Ciências e Letras, Universidade Estadual Paulista "Júlio de Mesquita Filho", Araraquara, 2017.

BELLO, A. Análisis ideologico de la conjugación castellana. Caracas: Plan Cultural Caracas, 1972.

BELLO, A. Gramática de la lengua castellana. Madrid: EDAF, 2004.

BENVENISTE, É. Problemas de linguística geral. 2 ed. Trad. Eduardo Guimarães. Campinas: Pontes, 2006. 2 v.

CARTAGENA, N. Los tiempos compuestos. In: BOSQUE, I; DEMONTE, V. Gramática descriptiva de la lengua española. Madrid: Espasa, 1999. 2 v. p. 2933-2975.

CASTILHO, A. T. A sintaxe do verbo e os tempos do passado em português. Alfa, Marília, v.9, p.105-153, 1966.

COMRIE, B. Aspect. Cambridge: Cambridge University Press, 1976.

COMRIE, B. Tense. Cambridge: Cambridge University Press, 2000.

FERRER, M. C.; SANCHEZ LANZA, C. Discurso Coloquial: El verbo. Rosario: UNR, 2000.

FREITAG, R. M. K. Tempo na frase e tempo no texto: as teorias de Reichenbach e de Rojo \& Veiga. Linguagem em (Dis)curso, Tubarão, v. 5, n.2, p. 389-413, 2005.

GARCÍA DE DIEGO, V. Gramática histórica española. Madrid: Gredos, 1951.

GILI GAYA, S. Curso superior de sintaxis española. 9 ed. Barcelona: Biblograf, 1970.

GUTIÉRREZ ARAUS, M L. Formas temporales del pasado de indicativo. 2 ed. Madrid: Arco Libros, 1997

GUTIÉRREZ ARAUS, M L Caracterización de las funciones del pretérito perfecto en el español de América. In: CONGRESO INTERNACIONAL DE LA LENGUA ESPAÑOLA, 2 2001 , Valladolid. Paneles y ponencias del II Congreso Internacional de la Lengua Española. Madrid: Centro Virtual Cervantes, 2001.

GUY, G R.; ZILLES, A. Sociolinguística quantitativa. São Paulo: Parábola, 2007.

HERNÁNDEZ ALONSO, C. Gramática funcional del español. 3 ed. Madrid: Gredos, 1996.

HOWE, C; RODRÍGUEZ LOURO, C. Peripheral Envelopes: Spanish Perfects in the Variable Context. In: CARVALHO, Ana Maria; BEAUDRIE, Sara (Eds). Selected Proceedings of the 6th Workshop on Spanish Sociolinguistics. Somerville, MA: Cascadilla Proceedings Project, 2013. p. 41-52.

JARA YUPANQUI, I. M. El pretérito perfecto simple y el pretérito perfecto compuesto en las variedades del español peninsular y americano. Signo e Seña. Buenos Aires, n. 20, p.255-281, 2009.

KANY, C. E. Sintaxis hispanoamericana. Trad. Martín Blanco Álvarez. Madrid: Gredos, 1970. 
KOVACCI, O. El comentario gramatical: teoría y práctica. Madrid: Arco Libros, 1992. 2 v.

KUBARTH, H. El uso del pretérito simple y compuesto en el español habladi de Buenos Aires. LUNA TRAILL, Elizabeth Guadalupe (Coord). Scripta philologica: in honorem Juan M. Lope Blanch. Ciudad de México, 1992. 2 v. p.553-566.

LAMIQUIZ IBAÑEZ, V. El sistema verbal del español actual. Revista de la Universidad de Madrid: Homenaje a Menéndez Pidal. Madrid, v. 18, p.242-267, 1969.

LENZ, R. La oración y sus partes. Madrid: Centro de Estudios Históricos, 1920.

MORENO FERNÁNDEZ, F. Qué español enseñar. Madrid: Arco Libros, 2000.

MÚGICA, N. Acerca de la tensión norma - variación lingüística. Sintaxis, morfología, léxico. Revista Virtual de Estudos da Linguagem. v. 5, n. 9, 2007.

NEBRIJA, A. Gramática de la lengua castellana. Madrid: Editora Nacional, 1980.

OLIVEIRA, L. C. As duas formas do pretérito perfeito em espanbol: análise de corpus. 2007. $130 \mathrm{f}$. Dissertação (Mestrado em Linguística) - Universidade Federal de Santa Catarina, Florianópolis, 2007.

PORTO DAPENA, J. Tiempos y formas no personales del verbo. Madrid: Arco Libros, 1989

QUESADA PACHECO, M. Á. El sistema verbal del español de América: de la temporalidad a la espectualidad. Español Actual, Madrid, n. 75, p.5-26, 2001.

RAE. Esbozo de una nueva gramática de la lengua española. Madrid: Espasa, 1986.

RAE. Nueva gramática de la lengua española: Morfología y Sintaxis I. Madrid: Espasa, 2009.

RAE. Manual de la nueva gramática de la lengua española. Madrid: Espasa, 2010.

REICHENBACH, H. The tenses of verbs. In: STEVEN, D.; GILLON, B. S. (Orgs.). Semantics: a reader. New York: Oxford University Press, 2004. p.526-533.

RODRÍGUEZ LOURO, C. Usos del Presente Perfecto y el Pretérito en el español rioplatense argentino. In: CONGRESO INTERNACIONAL DE ALFAL, 15, 2008, Montevideo. Actas del XV Congreso Internacional de ALFAL. Montevideo: Alfal, 2008.

RODRÍGUEZ LOURO, C. A sociolinguistic study of Preterit and Present Perfect usage in contemporary and earlier Argentina. 2009. 288 f. Tese (Doutorado em Filosofia) - School of Languages and Linguistics, Faculty of Arts , University of Melbourne. Melbourne, 2009.

RODRÍGUEZ LOURO, C; JARA YUPANKI, M. Otra mirada a los processos de gramaticalización del presente perfecto en español: Perú y Argentina. Studies in hispanic and lusophone linguistics. Minnesota, v. 4.1, p.55-80, 2011.

ROJO, G. La temporalidad verbal en español. Verba: Anuário Gallego de Filología, Santiago de Compostela, v. 1, p.69-149, 1974.

ROJO, G. Relaciones entre temporalidad y aspecto en el verbo español. In: BOSQUE, I. (Org.). Tiempo y aspecto en español. Madrid: Cátedra, 1990. p.17-43.

ROJO, G; VEIGA, A. El tiempo verbal: los tiempos simples. In: BOSQUE, I.; DEMONTE, V. Gramática descriptiva de la lengua española. Madrid: Espasa, 1999. 2 v. p.2867-2934. 
SANKOFF, D.; TAGLIAMONTE, S. A.; SMITH, E. Goldvarb Yosemite: a variable rule application for Macintosh. Toronto: Department of Linguistics, University of Toronto. 2015.

SCHWENTER, S.A., CACOULLOS, R. T. Defaults and indeterminacy in temporal grammaticalization: The 'perfect' road to perfective. Language variation and Change, v 20, p. 1-39, 2008.

TAGLIAMONTE, S. A. Analysing sociolinguistic variation. New York: Cambridge University Press, 2006.

TAGLIAMONTE, S. A. Variationist sociolinguistics: change, observation, interpretation. Chichester: Wiley-Blackwell, 2012.

TORREGO, L. G. Gramática didáctica del español. 8 ed. Madrid: SM, 2002.

VIDAL DE BATTINI, B. E. El español de la Argentina: Estudio destinado a los maestros de las escuelas primarias. Buenos Aires: Consejo Nacional de Educación, 1964.

WEINREICH, Uriel; LABOV, Willian; HERZOG, Marvin I. Fundamentos empíricos para uma mudança linguística. Trad. Marcos Bagno. São Paulo: Parábola, 2006.

Recebido em: $28 / 11 / 2017$

Aprovado em: 26/01/2018

Publicado em: 01/03/2018 